\title{
A POBREZA NA ESPANHA SETECENTISTA: O DIAGNÓSTICO ILUSTRADO
}

Earle Macarthy Moreira*

A evidência do pauperismo na Espanha do Século XVIII, não bastasse entrar pelos olhos e ouvidos ou, atrozmente, sentido pelo olfato, era ademais atestado por uma infinidade de relatórios,censos, memorandos, portarias, discursos e sermões produzidos pelas mais diversas autoridades e repartições, governamentais e eclesiásticas. Não era, portanto, motivo de discussão o fato em si; eram-no, todavia, as suas causas. Identificá-las, diagnosticá-las, significava para a maioria daqueles que preocupavam-se com a solução do problema, encontrar os caminhos por onde deveria correr ação do Estado no sentido de reverter o quadro.

A bem da verdade, a maioria referida era, de fato, uma minoria, uma elite reformista, em boa parte enquadrada pelo Estado, ocupante de cargos públicos, "integrada por modernizadores paternalistas e por patriotas ilustrados no sentido setecentista da palavra". ${ }^{1}$ Arquitetos de quantas reformas foram intentadas no século passado e mesmo inspiradores de algumas do atual, ainda que representem um alento de renovação de indiscutível mérito, marcaram a sua atuação por uma explícita falta de fé na capacidade de autoregeneração do "povo vulgar e imbecil", no dizer de um dos arautos do grupo. $^{2}$

Os resultados alcançados na identificação das causas da pobreza são dignos de nota, embora o mesmo não se possa dizer das ações corretivas, na maioria dos casos postas a perder por seu radicalismo extemporâneo, pela resistência de estruturas multicentenárias e pela conjuntura desfavorável.

* Professor no Curso de Pós-Graduação em História da PUCRS.

CARR, R. España 1808 - 1939. 7. ed. Barcelona: Ariel, 1979, p. 73.

2 Id., ib., p. 82.

Estudos Ibero-Americanos. PUCRS, v. XXIII, n. 1, p. 33-46, junho, 1997 
Não se pode exigir, claro está, que o pugilo de "ilustrados" que procurava regenerar o combalido organismo do Estado espanhol atinasse, na ordem prática das coisas, com soluções que revertessem, a curto prazo, o quadro com que se deparavam.

O primeiro dos obstáculos que, na maior parte das vezes, não foi possivel eliminar e, em contadas ocasiões, mal puderam contornar, diz respeito a uma questão de mentalidade. Na medida em que se enfrentam com tabus sociais ogeriza pelos ofícios mecânicos, "baixos e vis"; mania de grandeza; deificação da pobreza - não dispõem de um arsenal que ultrapasse o empírico, para implementar a ação.

Os anseios de enobrecimento deitam suas raizes nas profundezas da Idade Média, mas, sem dúvida, encontram vento a favor nas transformações econômicas dos séculos XI e XII e nos moldes não muito rígidos da sociedade feudal espanhola. É lá que o processo de aquisição do estatuto de nobreza cresce tanto que termina por banir, quase que por completo, o vocábulo burguesia da terminologia corrente, seja ela popular, literária ou oficial. ${ }^{3}$

A alta nobreza tendia a fechar-se num círculo bastante estreito, ainda que não de todo intransponível. A pequena nobreza, todavia, abria-se, com relativa facilidade, ao acesso de novos postulantes, o que terminará por ser uma peculiaridade tipicamente espanhola, se levado em conta o contexto europeu. E, nesse último grupo, já no final da Reconquista, mais e mais se diversificam os estratos, tanto economica como socialmente, a ponto de ser dificil distinguir-se, na prática, um fidalgo de um camponês. ${ }^{4}$

Como quer que seja, é inegável a sedução exercida no conjunto da sociedade, dos Reis Católicos em diante, pelas chamadas prerrogativas da nobreza, a qual, quanto mais se fortalecia o poder real, mais pugnava por garantias legais que as perpetuassem.

Onde isso foi parar, reporta-nos um dos homens mais lúcidos de seu tempo, José del Campillo y Cossío (1694-1764), cujo cursus honorum registra os altos cargos de Intendente Geral de Aragão, Secretário de Estado e da Fazenda, Secretário do Despacho Universal da Marinha, da Guerra e das Índias, Conselheiro de Estado, etc. Levando a sério a máxima de que "quem avisa, amigo é", não eludiu os riscos do desfavor pronunciando-se crua e objetivamente sobre o problema:

3 Cf. S. SOBREQUES. La Baja Edad Media Peninsular. In: VICENS VIVES, J. (Dir.) Historia social y económica de España y América. Barcelona: Vicens-Vives, 1974. v. 2, p. 93.

4 Id., ib., p. 115. 
A grande multidão de nobres famintos que próvida nossa Espanha, tão infeliz por isso, nos oferece, não é outra coisa que um formidável exército de abandonados. Geralmente, o que nasceu nobre mas sem conveniências conhece as prerrogativas de seu nascimento, mas não distingue a miséria de sua fortuna, antes quer que esta seja adjacente daquele; sendo infeliz, não adverte que se a nobreza encontra-se feita, a fortuna é preciso fazê-la. Cria-se, embora pobre, alentando aquela honra em que seus pais, constituídos talvez no mesmo deplorável estado, o influem, sem lembrar-se de dar-lhe exercício onde com as fadigas do trabalho pudesse satisfazer a precisão de comer; vive depois, ainda que miserável, produzindo a cada passo as ações de seus ascendentes, sem penetrar que louva o alheio quando a seus antepassados celebra; tem por vitupério a seu berço submeter-se ao trabalho... Ultimamente vivem ... tão envilecidos, que são o contágio dos povos, a peste da Corte e o descrédito do reino. ${ }^{5}$

O empobrecimento de vastos setores da pequena nobreza, especialmente do século XVII para o XVIII, se afetou o prestígio social e mesmo político da categoria, não impediu que nela se cevasse o Estado absolutista para engordar seus quadros administrativos e militares. A própria Igreja nela abasteceu-se para montar a maior parte de suas hierarquias.

Tudo isso contribui, com o tempo, para engrossar o caudal de indivíduos do estamento nobiliário bem como o acúmulo de seus privilégios, que, caso a caso, podiam ser muito mais teóricos que práticos, mas que, no conjunto, pesavam demasiado na economia do país.

Concentração de renda, isenções de toda ordem, inchaço e ineficiencia do aparelho estatal, são algumas das evidências que se destacam nesse quadro. Fidalguias de bragueta ou de gotera, de sangre ou de cuatro costados. Não importava quão tênue ou risível fosse a linha demarcatória entre umas e outras. Importava, sim, seu custo social,porque seguindo-lhe o exemplo "as pessoas da plebe desdenham trabalhar nas fábricas, construções e oficinas, e destinam seus filhos a outras carreiras, nas quais para cada um que se ganha, perdem-se mil. Daqui resulta a vagabundagem, o despovoamento, os delitos e a miséria que em geral se vê...". ${ }^{6}$ Era o funesto efeito multiplicador da vaidade

5 JOSE DEL CAMPILLO. Lo que hay de más y de menos en España para que sea lo que debe ser y no lo que es. Madrid: A. Elorza, 1969. p. 51. In: TUÑÓN DE LARA, M. Historia de España. Barcelona: Labor, 1985. t. XII, p. 39-40.

6 P. ALONSO. Catón Español Politico Cristiano. Madrid: 1800, p. 208-9. Ap. SANCHEZ AGESTA, L. El pensamiento politico del despotismo ilustrado. Sevilha: Univ. de Sevilha, 1979. p. 142. 
nobiliária - "verdadeira praga social da Espanha dos Áustrias", no dizer de Juan Reglá, mas que não esteve ausente da Espanha dos Bourbon. Conforme J. Mercader e A. Domínguez:

A aspiração à fidalguia estava muito espalhada entre os espanhóis dessa época. Em parte por pura vaidade, mas também porque conferia privilégios, como a exclusão do serviço militar e da obrigação dos alojamentos. O fidalgo não podia ser encarcerado por causa de dividas (a menos que fossem para com a Fazenda Real). Sua casa, seus cavalos e seu armamento eram sempre inembargáveis. Por delitos criminais, tão somente o aguazil-mor da Audiência podia detê-lo. Para os nobres havia, ademais, uma prisão à parte. Outra prerrogativa dos que gozavam do foro nobiliário ou militar era o poder esculpir na porta de sua casa o brasão de seu avoengo e receber de todos o tratamento de Don.?

Fidalguia que proporcionava brasões, mas que esterilizava as pessoas como membros produtores da sociedade.

Como o trabalho braçal, por preceito legal, incapacitava para a fidalguia, é de ver-se que a ninguém apetecia. Conclusão compartilhada por Campomanes, Floridablanca e Jovellanos, que encontravam aí o porquê do menospreso popular em relação a ofícios e artes mecânicas, em tudo e por tudo contrário ao bem comum.

Sendo assim, qualquer plano de desenvolvimento econômico não tinha como deixar de passar por um grande investimento na educação nacional, nisso incluindo-se tanto a base como o topo da pirâmide social: povo e elites; escolas de primeiras letras e universidades. Só desterrando-se a ignorância e a preguiça, "raizes de todos os males e de todos os vícios", é que seria possível mudar o lamentável estado do campo espanhol, cheio de "homens tristes, de escuro e sujo porte, casas de barro cheias de imundície, aldeias, enfim, sem felicidade". 8

De igual modo, só um programa de ação social bem dirigido poderia devolver às artes e ofícios o necessário prestígio, capaz de atrair o interesse dos jovens das urbes e aldeias. É o que virá a propor Campomanes no "Discurso sobre a educação popular", em 1775:

7 In: VICENS VIVES, op. cit., v. 3, p. 53 e v. 4, p. 48.

8 JOVELLANOS, Gaspar Melchor de. Diarios. Madrid: Alianza, 1967. [Cf. anotações de 1793 e 1795]. 
É necessário, também, apagar dos ofícios toda a desonra e habilitar aos que os exercem para os empregos municipais da República. Em uma Nação cheia de honra, como a espanhola, convém muito não perder de vista esta máxima, que produz tão bons efeitos na Catalunha e em outras Províncias do Reino: só a vadiagem deve contrair a vilania. ${ }^{9}$

O estrangeiro que percorria a Espanha, mas não a penetrava em sua essencialidade, emitia juizos de valor apressados e entrava em generalizações descabidas. Quando o Marquês de Aubeterre lá esteve como embaixador, em 1759 , não teve dúvida em associar o atraso existente em relação ao restante da Europa ocidental - "séculos de atraso, quando menos" - ao fato de que "as populações são preguiçosas e pouco trabalhadoras". O Duque des Cars, por sua vez, em 1782, escreveu em suas "Memórias" (publicadas em 1890), que na Espanha "era um princípio absoluto fazer sempre o que se havia feito no dia anterior e fazê-lo absolutamente da maneira como já se havia feito". ${ }^{10}$

Eram desconsideradas, nessas análises feitas pela rama, situações tais como as do centro da Península, cujas condições climáticas adversas, que abrangiam vastas extensões de terras semi-áridas, as sujeitavam aos efeitos devastadores da erosão e de um regime de chuvas escassas. Isso, associado a um relevo malpropício à irrigação, podia determinar um tendência acentuada à monocultura. $\mathrm{O}$ mesmo se pode dizer de outros fatores como, por exemplo, o excessivo parcelamento das propriedades que, na Galícia, chegavam por vezes a menos de um hectare e onde havia casos de subdivisões - em consequência do crescimento demográfico e do costume que lá regia a divisão das heranças - que afrontam até hoje a imaginação mais audaciosa. ${ }^{11}$

Mesmo Ward, um dos melhores economistas da época, deixou-se levar por um raciocínio simplista, na medida em que reduzia praticamente todo o problema a uma questão de mão-de-obra sobrante, mais terra sobrante, igual a mais terra cultivável, maior população e economia mais rica:

9 CAMPOMANES, Conde de. Discurso sobre la educación popular de los artesanos y su fomento. Madrid: Sancha,1775-1777. v. 1.p. 119. [Na verdade, trata-se de um texto de Rubín de Celis, corrigido e aumentado por Campomanes]. In: TUÑ́́N DE LARA, op. cit, t. XII, p. 68.

10 Ap. SARRAILH, J. La España ilustrada de la segunda mitad del siglo XVIII. México: FCE, 1957. p. 2.

11 CARR, op. cit., p. 24, n. 23: "Um exemplo de nossos dias: uma superficie de 117 hectares está repartida entre 263 proprietários e dividida em 2.486 parcelas...”. 
... se nossos Espanhóis não ocupassem mais terreno do que podem cultivar, ficariam, e póde-se assegurar que hoje em dia ficam, três quintas partes do Reino sem habitantes e sem cultivo; de sorte que se contém a Espanha, como se crê, vinte e cinco mil léguas quadradas, e segundo o Marechal de Vauban a França tem trinta mil, sobrarão quinze mil léguas quadradas sem utilizar-se, nas quais haverá sem dúvida dez mil de boa terra, que bastariam para manter de dez a doze milhões de habitantes mais. ${ }^{12}$

Em suma, de uma agricultura mais rendosa dependia o futuro da Espanha; só assim poderia sustentar o crescimento demográfico, interno e ultramarino, e compensar sua própria defasagem no processo da revolução industrial em curso. Estava em jogo sua recuperação no ranking das potências de primeira grandeza.

Com um sistema de governo autoritário e centralista, é bem de ver que boas cabeças como o citado Ward, e na sua esteira muitos outros, no afã de encontrar uma legislação que pudesse atender, em geral, todas as províncias da monarquia, não conseguiram resultados práticos apreciáveis dada a grande diversificação regional. $\mathrm{E}$, às vezes, onde viam atraso, nada mais era senão uma eficiente adaptação às condições locais, ao longo de séculos de luta contra uma natureza ingrata.

Nas Províncias Vascongadas, por exemplo, onde o mendigo era uma figura rara e o agricultor exemplarmente caprichoso, os métodos de cultivo Carr chama a atenção para isso - "eram em muitos aspectos arcaicos; o instrumento principal a laya [pá dentada, de cavar e revolver a terra], parecia um resíduo primitivo aos entusiastas do arado". ${ }^{13}$ No entanto, para terreno montanhoso nada mais adequado. O mesmo poder-se-ia dizer do arado de madeira, da foice, da eira e do alto forno de lenha.

"Fazemos o que faziam nossos pais" nem sempre era a manifestação de um camponês burro e teimoso, submetido à lei da inércia; era, freqüentemente, a resistência de quem, intuitivamente, desconfiava das mãos manicuradas dos letrados, que de cultivo do solo conheciam apenas as gravuras dos livros importados da França ou da Inglaterra:

12 WARD, Bernardo. Proyecto económico en que se proponen varias providencias dirigidas a promover los intereses de España con los medios y fondos necesarios para su plantificación. Escrito en el año 1762. Madrid: 1779. In: TUÑÓN DE LARA, op. cit., t. XII, p. 55.

13 CARR, R. op. cit.,p. 21. 
O arado do camponês, no dizer dos críticos, "arranhava" o solo; mas um sulco profundo te-lo-ia tornado sem serventia. Os mulos eram "monstros estéreis" e "o pior dos males que afligem a nossa agricultura"; mas, o mulo é rápido no trabalho e resistente ao calor. Abusava-se do alqueive, mas o alqueive era indispensável para o sequeiro em terras pobres. ${ }^{14}$

Escapava à maior parte dos economistas que se havia latifúndio abusivo, em se tratando de terras pobres, não apropriadas ao cultivo intensivo e continuado, o loteamento puro e simples não resolvia nada e estabelecer comparações entre o rendimento do camponês inglês e do espanhol, desconsiderando a geografia física, era puro exercício de imaginação fantasiosa.

Tudo isso não invalida, porém, o referendo de Sarrailh quanto à real existência do "peso da rotina", detectado nos escritos da elite ilustrada; apenas reduz a dimensões mais próximas da realidade os tais "preconceitos que [o agricultor] mamou com o leite", no dizer de Cavanilles. ${ }^{15}$

A resistência às inovações no uso de novas tecnologias, contrariando até mesmo as evidências, pôde ser contornada quando o discurso ilustrado se fez acompanhar dos meios materiais capazes de comprová-las. Foi o caso da introdução do tear de Vaucanson, que enfrentou, de início, a hostilidade dos camponeses de Valência. Não bastou para demovê-los a campanha feita no púlpito, pelos sacerdotes da diocese. Entretanto, uma série de demonstrações práticas, realizadas com os tornos doados pela Junta de Comércio e Agricultura, resultou em triunfo sobre o preconceito. E isso se dá no curto espaço de tempo que medeia entre janeiro e agosto de 1791. É um típico exemplo dos bons resultados que podiam advir quando o poder público (municipalidade, juntas, etc.), elementos progressistas da comunidade (Sociedade de Amigos do País) e Igreja (arcebispo, clero), davam-se as mãos em prol do bem comum.

Por entender que era um fenômeno puramente cultural, que seria vencido apenas com medidas pedagógicas, Pablo de Olavide, em 1771 magistrado em Sevilha, inconformava-se: havendo conseguido com seus amigos o envio de alguns arados de roda, de tão bons resultados na Inglaterra, apesar de com eles fazer-se o trabalho mais depressa, a primitiva e "atrasada" laya não desaparecia.

14 Id. Ib., p. 39.

15 SARRAILH, op. cit., cap. II. 
Serviria de consolo ao bem-intencionado e impaciente Olavide saber mais um pouco sobre o que realmente se passava na Grã-Bretanha. Pela mesma época, um dos maiores nomes da agricultura britânica, Thomas William Coke ( 1754-1842), combinava ecléticamente, com o maior sucesso, os êxitos obtidos pelo visconde Charles Townsend em seus ermos domínios de Norfolk, convertidos em terras produtivas graças aos adubos e à rotação quadrienal (forragem, trigo, nabos, cevada ou aveia), com os de R. Bakevel, cuja granja modelo de Dishey se havia convertido em atração turística para gente de toda parte, que lá acorria atraída por seus canais de irrigação, suas soberbas searas e magnificos reprodutores, selecionados para um melhor rendimento de carne.

Em sua propriedade de Holkham, Coke estadeava os bons resultados das terras adubadas, semeadas em linha com semeadora mecânica, do cultivo do trigo associado com nabos, batatas e beterrabas, que serviam para alimentar os animais estabulados além de regenerar o solo. Sabiam todos, por ser voz corrente, que o rendimento de Holkham havia pulado de 2.200 para 20.000 libras anuais. No entanto, seus vizinhos mais próximos tardaram não menos de quinze anos para imitá-lo. ${ }^{16}$

Sem dar-se conta, o rústico peninsular que desconfiava da eficácia da adubagem para melhoria das lavouras ou dos novos métodos de semeadura, aferrado que permanecia ao pré-histórico voleo - o nosso velho "a lanço" estava tomando uma atitude compartilhada pelo papa da agronomia mediterrânica, Jethro Tull (1674-1741) :

Rejeita o estrume, cujo papel não entende; tudo para ele depende da água que as plantas vão buscar no solo; dai que a chave da nova agricultura resida nas lavras profundas e repetidas. ${ }^{17}$

Chave mágica, mas contra-indicada, como já se viu, para abrir as portas da prosperidade a boa parte dos campônios pobres da Espanha. Se o espanhol resistia a cultivar a ruiva ou garanza, da qual extraía-se uma tinta vermelha de largo uso nas fábricas de corantes da Catalunha, seu congênere francês, considerado mais adiantado, resistia, igualmente, a todos os esforços governamentais quanto ao cultivo da batata, cuja difusão já ocorrera na Inglaterra e

16 Cf. CHAMBERS, J. D. \& MINGAY, G. E. The agricultural revolution, 1750-1880. 3. ed. Londres: Batsford Books, 1968; ERNLE, Lord. Histoire rurale d'Angleterre. Paris: Gallimard, 1952.

17 CHAUNU, P. A civilização da Europa das Luzes. Lisboa: Estampa, 1985. v. II, p. 21. 
Irlanda, em fins do século anterior, graças à sua capacidade de sobreviver a nevascas tardias. Só em decorrência das más colheitas de grãos de 1788 e 1793, ou seja, durante a Revolução, é que a batata ganhou terreno, especialmente no Maciço Central e na Bretanha.

Forçoso é convir, portanto que a resistência camponesa a novidades não era peculiaridade tipicamente espanhola, por ser o peninsular menos isto ou mais aquilo. Estava por toda a parte e vem até hoje: que o digam os extensionistas rurais de nossos dias.

Da hostilidade dos camponeses castelhanos para com as árvores diz bem o inglês Bowles em uma "Introdução à história natural e à geografia física da Espanha”, traduzida e publicada em Madrid no ano de 1782, quando refere 0 fato de que os lavradores de ambas as Castelas refugavam o plantio de árvores, com o argumento de que além de tirarem lugar das lavouras, atraíam e multiplicavam os pássaros, em especial os pardais, cuja voracidade é proverbial. Daí a paisagem desolada das planuras castelhanas que pela cor, à distância, confundia-se com o solo. ${ }^{18}$

Sendo um dos maiores problemas da agricultura espanhola a falta de água, a importância do reflorestamento não escapava à elite ilustrada, conforme pode-se perceber a cada página dos "Diários" de Jovellanos, revelando a sua face de preservacionista e ecologista. No programa de governo de Floridablanca, a chamada "Instrução reservada...", de 1787, nos itens LXXVII, LXXVIII e LXXIX, trata expressamente das regras para o reflorestamento e incentivos respectivos. Assinala que "a sombra das árvores impede em grande parte a evaporação das águas", que "em muito ajudarão aos plantios os regos, aproveitando-se as ribeiras dos rios, valos ou canais, torrentes ou arroios, como também os açudes". Era preciso recuperar essa riqueza, pois "a cada dia aumenta a falta de lenha, de madeiras e de carvão, e assim não admitem dilação as providências necessárias para o remédio". Sugere o plantio de árvores nos terrenos baldios, depois de demarcados e sorteados entre os camponeses, e que os frutos das mesmas fossem para eles. Aos possuidores de terrenos incultos ou ocupantes de pastos de uso comum, deveria ser facultado cercar e aproveitar a metade ou a terça parte dos que plantassem de novo, se conservassem o que já estava arborizado. Era preciso ter cuidado com a erosão e "por uma parte se interessa à agricultura e mesmo ao povoamento que as terras sejam aproveitadas com semeaduras e cultivos,

18 Ap. SARRAILH, op. cit., p. 47; CARR, op. cit., p. 26-7. 
por outra, é contra a própria agricultura o destruir, por esse motivo, as florestas já plantadas e úteis para arvoredos, lenhas e madeira". ${ }^{19}$

A ação pedagógica, sozinha, não alcançava resolver tantos problemas, aqui apenas arrolados alguns por mais evidentes ou insólitos. Mas, quaisquer outras soluções, com pretensões a perdurar, inevitavelmente, ou teriam que ser precedidas por ela ou acompanhá-la passo a passo.

A atitude padrão européia foi enfrentar o desafio do futuro, onde o progresso adquiria um ritmo cada vez mais acelerado, apelando para a implementação do ensino elementar mediante uma decidida intervenção do Estado. Mesmo a França, com toda a sua tradição de declinar nas mãos das congregações religiosas o ensino das camadas populares, não se esquivou ao repto e no que tange a artes e ofícios chegou, em certos momentos, a liderar. Tal o caso da Escola Real de Desenho, em Paris, que fundada em 1767 chegou a acolher 1.500 alunos de mais de oito anos, gratuitamente. ${ }^{20}$

Em agosto de 1763, Frederico, o Grande institui o General-Landschule Reglement e impõe o ensino primário obrigatório para as crianças de 5 a 13 anos, apesar da oposição dos latifundiários e da carência, naquele momento, de professores qualificados. Em menos de dez anos, com a subsequente reforma do ensino superior, foi possível melhorar a qualidade dos professores -muitos dos quais oriundos dos quartéis- o que, a médio prazo produziu os melhores resultados:

Em trinta anos, a Prússia, essa incerta Alemanha eslava,essa colônia retardatária para téenicos estrangeiros, esse terreno privilegiado de manobra da diáspora huguenote, conseguiu uma das mais belas recuperações de toda a história. A escola prussiana, filha da caserna, prepara a Alemanha dos prêmios Nobel dos anos 1890-1930. ${ }^{21}$

Essa, aliás, não foi uma atitude isolada entre os príncipes alemães. Depois de um primeiro intento fracassado, na década de 1740, no sentido de tornar obrigatório o ensino primário, a Mogúncia na gestão do Eleitor

19 Instrucción reservada que la Junta de Estado creada formalmente por mi decreto de este dia 8 de julio de 1787 deberá observar en todos los puntos y ramos encargados a su conocimiento y examen. In: Obras originales de Floridablanca. Madrid: Atlas, 1952. (BAE, LIX), p. 224-5. (As instruções de número LXIX a LXXXIV estão transcritas em TUÑ́́N de LARA, op. cit., t.XII, p. 82-6.)

20 MOUSNIER, R. e LABROUSSE, E. O século XVIII. In: CROUZET. M. (Dir). História Geral das Civilizações. São Paulo: DIFEL, 1957. t. V, v. 1, p. 157.

21 CHAUNU, op. cit., p. 142. 
Emmerich Joseph (1763-74) avança nas reformas; cria uma nova escola de magistério para melhorar o nivel do professorado, revisa e atualiza os livros de texto e expande a escolarização.

Maria Teresa da Áustria, em 1774, pela General Schlordnung, acompanha o exemplo de Frederico II e também subvenciona o ensino elementar, no que é, por sua vez, imitada por Catarina II da Rússia em 1786. Como bem observa Pierre Chaunu:

A alfabetização constitui uma etapa fundamental; só a alfabetização total pode dar possibilidades de vingar a revolução téenica que é, antes demais nada, uma revolução mental. [...] Os humildes alfabetizados não estão de modo algum em vias de sair para fora do campo da cultura tradicional, que continua a transmitir a sua herança por ouvir-dizer e verfazer; mas é no seu seio que as modificações dos gestos, a melhoria dos utensilios, a racionalização dos atos produtivos são mais suscetiveis de se produzir e de se propagar. ${ }^{22}$

Luís XIV, com intuição de estadista, já em 1698 se havia dado conta de que seus sonhos de grandeza para a França deveriam passar, forçosamente, pela escola elementar generalizada. Isso para não falar da Inglaterra, cuja população masculina em 1800, no take off da Revolução Industrial já estava entre 65 a $75 \%$ alfabetizada.

No momento mesmo em que as demais nações européias atacavam com vigor o analfabetismo e enveredavam pelo ensino técnico, abrindo por aí uma via para o futuro, na Espanha continua enorme o número dos que não sabem ler nem escrever:

O ensino primário estava a cargo de professores cuja formação era muito deficiente. As Universidades escapavam ao controle dos monarcas, por seus privilégios e imunidades. Os métodos de ensino eram rotineiros e os ensinamentos estavam impregnados de aristotelismo e escolástica. Havia um grande desprezo por tudo quanto significasse observação e experimentação. ${ }^{23}$

Essa situação, no meio rural, não tem paralelo, a não ser na Rússia. É a miséria espiritual que faz mais trágico o destino das massas camponesas,

22 Id. Ib., v. I, p. 134.

23 ANES, G. El Antiguo Régimen: Los Borbones. In: ARTOLA, M. Historia de España Alfaguara. Madrid: Alianza Universidad, 1976. t. IV, p. 453. 
incapacitando-as ao aggiornamento, mesmo no médio e longo prazo, em relação ao progresso tecnológico e aos avanços no conhecimento e domínio da natureza. Alguns dos exemplos arrolados revelam que à força de erros e acertos, ao longo de gerações e gerações, o camponês espanhol chegou a conviver, mais ou menos satisfatoriamente, com seu meio ambiente. A ignorância, porém, a superstição e a rotina formam o contrapeso negativo dessa convivência, na qual se a rotina é a âncora do sobreviver, é também a maneia do progresso.

Para sacudir essa gente de seu torpor, de sua acomodação, o ensino fazíase presente com escolas - quando as havia - pródigas em sopapos e palmatórias, na base de "a letra com sangue entra", providas de mestres nécios e amargurados, cujo salário mal dava para uma comida diária e que, tão logo podiam, debandavam para as cidades maiores, abandonando aldeias e povoados, cujos habitantes ricos ou pobres ficavam sumidos na ignorância. ${ }^{24}$

O campo da história das mentalidades - porque no fundo é disso que se trata - inexistente então, ainda hoje é terreno minado. Sua vastidão, heterogeneidade, fluidez, constituem objeto de fascinação para todos quantos nele lavram: cientistas sociais, antropólogos, políticos, historiadores. Mas, em vez de concentrarem o feixe de luz, dispersam-no por muitos desvios que, por sua vez, conduzem a muitas e diferentes respostas.

Convém recordar que para resgatar da linguagem comum o termo "mentalidades", no sentido de comportamentos, de sistemas de atitudes e formas de espírito coletivas, foi preciso que Lévy-Bruhl indagasse meia vida até chegar a publicar, em 1910, Les fonctions mentales dans les sociétés inferieures e levasse mais doze anos para lançar à discussão La mentalité primitive, onde os comportamentos pré-lógicos ou emocionais são apreciados no interior mesmo dos conjuntos sociais. Quase que simultaneamente, em 1911, Henry Berr, em La synthèse en histoire, deixa claro que as transformações só podem ser perfeitamente compreendidas se em termos de evolução psicológica. Na ciência dos comportamentos está a chave do entendimento histórico. E Lucien Febvre, ao cabo de mais um decênio de estudos e debates, chega a ser taxativo: “...os fatos econômicos são, como todos

24 Cf. TORRES VILLARROEL, Diego de. Vida. Madrid: La Lectura, 1912. (Clásicos Castellanos, 7), p. 37; ZARATE, Gil de. De la instrucción pública en España. Madrid 1855. t. I, p. 243; ISLA, Pe. J. F. de. Historia del famoso predicador Fray Gerundio de Campazas, aliás Zotes. In: Obras escogidas del padre... Madrid: Rivadeneyra, 1850. (B.A.E., XV), p. 78-80. 
os outros fatos sociais, fatos de crença e de opinião". Com isso, aliás, remete ao limbo as leituras anacrônicas do passado, com suas abstrações e intemporalidades, ressaltando o confronto entre o homem singular e o universo mental no qual ele intervém. ${ }^{25}$

Nada disso, porém, esteve à disposição dos "ilustrados" espanhóis. Como tantos reformistas de seu tempo, e outros que ainda estão por aí, não lhes ocorreu que reformas e imediatismo não se conjugam, antes se repelem. Exorcisar a tradição desdenhando-a como Feijóo ("vão e ostentoso título"), ou infamando-a como Campomanes que usava o vocábulo "tradicionária" para designar qualquer instituição incompetente, ou ainda denegrindo os "costumes de nossos avós" como o fez Cadalso nas Cartas marruecas, pouco mais revelaria que uma certa fé ingênua no progresso e na razão, não fora o novo e criador alento que deram à revitalização do rigor lógico, ao experimentalismo e à "luz da crítica racional para depurar a verdade".

Num século de agnósticos e ateus, o catolicismo de vários dos ilustrados, como Feijóo e Jovellanos, profundo e ortodoxo, "pesou sobre suas vidas e suas obras, salvando precisamente por esse matiz, toda a solução de continuidade com a linha clássica do pensamento espanhol". Nas verdades naturais da ciência, buscaram "o sinal de Deus". ${ }^{26}$

De qualquer modo, a ação do progressismo salvacionista na luta contra a rotina filha da ignorância, afigurava-se aos mais afoitos vitoriosa, se respaldada por ações fortes emanadas do governo. Outros, mais reflexivos e escaldados com os rumos tomados pela Revolução Francesa, acreditavam mais eficaz um trabalho pedagógico, de frutos a colher em médio ou longo prazo. É o caso de Jovellanos:

Estava persuadido,... de que o meio mais seguro de não fazer nada pelo bem de uma nação era o de querer fazê-lo todo, de uma só vez. O que urgia era preparar bem o terreno e depois semear, quer dizer, instruir e educar: a colheita - a ilustração e a felicidade de todos os homens - viria com o tempo. ${ }^{27}$

Jovellanos é, portanto, muito mais um reformador que um revolucionário. De fervoroso crente na eficácia dos decretos, evolui para a con-

25 Cf. REVEL, J. Mentalidades. In: Burguière, A. (Org.). Dicionário das Ciências Históricas. Rio de Janeiro: Imago, 1993. p. 528-35; DOSSE, F. A História em migalhas: dos "Annales" à "Nova História". 3. ed. São Paulo: Ensaio; Campinas: Editora da UEC, 1994. p. 84-93.

26 SANCHEZ AGESTA, op. cit., p. 13-19.

27 HELMAN, Edith. Jovellanos y Goya. Madrid: Taurus, 1970. p. 30. 
vicção de que pela força, pela imposição jupiteriana, não se chega a outro lugar senão a piorar a raça humana, com a crueldade erigida em sistema. As vicissitudes de sua própria vida e as circunstâncias de seu entorno, levaramno a repudiar qualquer sistema de governo privativo da liberdade. $\mathrm{O}$ bem geral não há de ser construido perdendo-se de vista a felicidade individual efetiva. Segundo Edith Helman, em um borrador onde aparece cópia de uma carta sua está: "Entendamo-nos. Louvo os que têm valor para dizer a verdade, aos que se sacrificam por ela; mas, não aos que sacrificam outros entes inocentes às suas opiniões que, pelo comum, não são mais que seus desejos pessoais, bons ou maus". E anota em seus Diarios, no dia 25 de junho de 1794: "Jamais acreditarei que se deve procurar para uma nação mais bem do que pode receber; levar mais adiante as reformas será ir para trás". ${ }^{28}$

Proféticas palavras, que o tempo encarregou-se de comprovar, mas cujos ensinamentos não têm comovido, até hoje, os políticos. 